\title{
İş Yerinde Zihinsel Yüklenme ve Egzersizin Kalp Hızı Değişkenliği Üzerindeki Etkisi
}

\author{
Osman ATEŞ ${ }^{* 1}$, Burçak KESKİN ${ }^{1}$, H. Birol ÇOTUK ${ }^{2}$ \\ ${ }^{1}$ İstanbulÜniversitesi Spor Bilimleri Fakültesi \\ ${ }^{2}$ Marmara Üniversitesi Spor Bilimleri Fakültesi
}

$\ddot{\mathbf{O} z}$

Orijinal Makale

Bu çalışma, İstanbul'da faaliyet gösteren büyük bir holdingin üst düzey yöneticileri ile bilgisayar mühendislerine uygulanmıştır. $\mathrm{Bu}$ çalışmanın amacı; iş yerinde zihinsel yüklenme ve egzersizin kalp hızı değişkenliği üzerindeki etkisini araştırmak ve karşılaştırmaktır. $\mathrm{Bu}$ araştırmaya katılan toplam 30 kişiden (18'i erkek ve 12'si bayan) oluşan grupta yaş ortalaması $37.4 \pm \mathrm{SD}$ tür. Üst düzey yöneticilerden 11 kişi $(9$ erkek-2 kadın), bilgisayar mühendislerinden 19 kişi (9 erkek-10 kadın) araştırmaya katılmıştır. Bütün katılımcılar demografik ve antropometrik verileri bir form ile toplanmıştır. Tüm katılımcıların kalp atım hızları birer hafta aralıkla iki gün ve günde iki ölçüm olmak üzere toplam dört kez birer saat boyunca kaydedilmiştir. Kalp atım hızları kaydı için kalp atım aralıklarını $1 \mathrm{~ms}$ hassaslıkta kaydedebilen polar 810i telemetrik nabız ölçer saat kullanılmıştır. Kalp hızı değişkenliği parametreleri zaman ve frekans boyutunda polar yazılımı ile belirlenmiştir. Tüm grubun tekrarlanan ölçüm parametrelerinin karşılaştırmaları için parametrik olmayan Friedman testi kullanılmıştır (anlamlılık sınırı $\mathrm{p}<0.05$ ). Kategoriler arsındaki farkı belirlemek için Mann-Whitney U testi kullanılmıştır (anlamlılık sınırı $\mathrm{p}<0.05$ ). Öznel stres ölçeği puanlarıyla kalp hızı değişkenliği ölçütleri arasındaki ilişkiyi belirlemek için Pearson korelasyonu kullanılmışıtır (anlamlılık sınırı $\mathrm{p}<0.05$ ). Kategoriler için yapılan karşılaştırmalarda ortalama kalp atım düzeyleri için bir fark bulunmazken. kalp hızı değişkenliği parametreleri için yöneticiler ile mühendisler arasında istatistiksel olarak anlamlı farklar tespit edilmiştir. Bu bağlamda HF yüksek frekans parametresi en belirgin farkı mühendisler lehine işaret eden parametre olmuştur. Öznel stres ölçeği puanlarıyla kalp hızı değişkenliği parametreleri arasında anlamlı bir korelasyon bulunmamaktadır. Sonuçta. yöneticilerin kalp hızı değişkenliği parametrelerinde görülen anlamlı düşüşlerin ciddi bir Yayın Bilgisi Gönderi Tarihi: 26.10 .2017 zihinsel yüklenmeye işaret etmektedir.

\section{The Effect of Cognitive Strain and Exercise at the Job Place on Heart Rate Variability}

\begin{abstract}
This study was conducted on senior managers and computer engineers of a big corporate holding in Istanbul. The goal of this study was to investigate and compare the effects cognitive strain and exercise on heart rate variability. 30 people participated in the study. The average age of the group (18 male and 12 female volunteers) was $37.4 \pm$ SD. Eleven senior managers ( 9 male and 2 female). and 19 computer engineers ( 9 male and 10 female) participated in the study. Demographic and anthropometric data of all participants were collected. Heart rate variability was recorded at four sessions on two days seperated by a week. For the recording Polar S810i telemetric heart rate watch was used (accuracy $1 \mathrm{~ms}$ ). Each recording lasted one hour. The time and frequency domain parameters of heart rate variability were calculated by the Polar software. The non-parametrical Friedman test was used for comparison of repeated measurement parameters of the whole group (significance level $\mathrm{p}<0.05)$. In order to determine the difference between categories the Mann-Whitney $\mathrm{U}$ test (significance level $\mathrm{p}<0.05$ ) was applied. Pearson correlation was for the correlation between the subjective stress scale and heart rate variability (significance level $\mathrm{p}<0.05$ ).
\end{abstract}

Original Article

\footnotetext{
* Sorumlu Yazar: Osman ATEŞ
} 
Neither were there differences among the various categories regarding the mean heart rate. But significant differences were found between senior managers and computer engineers for heart rate variability parameters. In this context HF high frequency power was the most predictive parameter in favour of the computer engineers. There was no significant correlation between a subjective stress scale and heart rate variability parameters. In conclusion. the significant deterioration of heart rate variability of the senior managers points to a heavy cognitive strain at the job place.

\section{GíRiș}

Günümüzde çalışanların çoğu, iş yerinde günlük mesaisinin büyük bir kısmını bilgisayar başında geçirmektedir. Bu kişiler yoğun bir görsel ve zihinsel yüklenme yaşamaktadırlar. Görsel ve zihinsel yüklenmeye birçok psiko-sosyal stresör eşlik etmektedir. Buna ek olarak sosyal desteğin azlığı ve bilgisayar becerisinin yetersizliği düşük iş hâkimiyetini meydana getirmektedir (Hjortskov ve ark., 2004). Psiko-sosyal stresörlerin yarattığı düşük iş hâkimiyeti kişilerde kardiyovasküler hastalıkları tetiklemektedir (Belkic ve ark., 2000). Düşük iş hakimiyeti Karasek'in belirttiği gibi mesleki yüklenme için geliştirilen 'talep-hakimiyet model' ve 'iş gerginliğinin ihtiyaç/kontrol modeli' ihtiyacın yüksek ve kontrolün düşük olduğu işlerin düşük sosyal destek ile birleşmesi sonucu stres miktarının arttığını ileri sürer (Karasek, 1979; Johnson, 1988). Stresin kişinin dış dünyasından talepleri ve bu şahsi taleplerini karşılamak için sahip olduğu kaynakların dengesizliği sonucu arttığı da belirtilmiştir (Frankenhaueuser ve ark., 1989). Stres, "bireyin fizik ve sosyal çevredeki uyumsuz koşullar nedeniyle, bedensel ve psikolojik sınırlarının ötesinde harcadığ 1 gayret" olarak tanımlamaktadır (Cüceloğlu, 2011: 321). Ayrıca stres kişilerin içinde bulundukları çevrenin istekleriyle baş edemediklerini hissettiklerinde yaşadıkları olumsuz duygular ve inançlar olarak betimlenebilir (Aronson-Wilson ve ark. 2012).

Fiziksel ve zihinsel yüklenmenin kombinasyonu kardiyovasküler yanıtı önemli bir şekilde etkilemektedir. Stresörler kalp hızı değişkenliği’ne (KHD) parasempatik sinir sistemi etkisini yansıtan yüksek frekanslı salınımların azalmasına neden olmaktadır. Buna karşılık düşük frekans/yüksek frekans oranı artmaktadır. Bu tür bir stres olayını yaşayan kişilerde sonrasındaki dinlenme döneminde bile kardiyovasküler yanıtlar sürebilmektedir ve kan basıncı yüksek kalmaya devam etmektedir. Uzun veya kısa süreli psiko-sosyal stresörleri inceleyen araştırmalarda. kısa süreyle etki eden psiko-sosyal stresörlerin parasempatik sinir sistemini inhibe ettikleri ve kalbin vagal modülasyonunu kestikleri; ayrıca kısa süreli stresörlerin bile sempatik sinir sistemi aktivitesini artırdığı bildirilmiştir (Acharya ve ark., 2004). Halen iş yerinde mevcut stresörlerin ayrıntılı bir değerlendirilmesi yapılmamıştır. İş yerinde gürültü, mesleki yüklenme ile vardiya çalışmasına bağlı uykusuzluk faktörlerinin KHD'ın olumsuz etkilediğini bildirmişlerdir. Sadece az iş talebi/ yüksek iş hâkimiyeti gösteren gruptaki işçilerde sağlıklı sayılabilecek KHD değerleri ölçülmüştür. Fiziksel aktivitenin yüksek olması veya egzersizin eklenmesiyle KHD değerlerinde de. yüksek salınımlı frekansların artmasına paralel bir artış bulunmuştur (Srouffe, 1971).

$\mathrm{Bu}$ çalışmamızda iş yerinde farklı statüde çalışan kişilerin. yönetici ve teknik uzmanların. kalp hızı değişkenliği bağlamında farklı tepkiler verip vermediği araştırılmıştır. Ayrıca değişik mesleki ve psiko-sosyal yüklenme durumları ile iş yeri ortamında rekreatif egzersizin kalp hızı değişkenliğgi üzerindeki etkisi araştırılmıştır. Araştırmanın amacı; iş 
yerinde zihinsel yüklenme ve egzersizin kalp atım hızı değişkenliği üzerindeki etkisini araştırmak ve karşılaştırmaktır. Hipotezlerimiz ise görev tanımı kategorileri arasında; kalp atım aralığı ortalamaları, zaman boyutu, frekans boyutu ile kalp atım hızı değişkenliğini gösteren ölçütler arasında istatistiksel olarak anlamlı bir fark yoktur.

\section{YÖNTEM}

\section{Çalışma Grubu}

Araştırmanın çalışma grubu İstanbul' da bir holding de çalışan tamamı bilgisayar mühendislerinden oluşan ancak farklı statülerde olan müdür (projeleri denetleyen ve sunan grup) ve takım elemanlarının (projelerden sorumlu olan ekip, tüm teknik çalışmaları yapan grup) katılımıyla gerçekleşmiştir. Toplam 30 kişidir. Katılımcıların, 18'i erkek ve 12'si bayandan oluşan bu grupta; yaş ortalaması $37.4 \pm$ SD tür. Üst düzey yöneticilerden 11 kişi 9 erkek- 2 kadın, bilgisayar mühendislerinden 19 kişi 9 erkek-10 kadın bu araştırmaya katılmıştır. Katılımcıların her birinden dört kalp atım hızı kayıt'ı alınmıştır. Bu kayıtlar farklı iki günde ve gün içinde iki (sabah; kayıt 1-kayıt 3, akşam üstü; kayıt 2-kayıt 4) kere olacak şekilde, çalışma düzenini bozmayacak günlük aktivitelerini engellemeyecek biçimde yapılmıştır. Katılımcılar ilk kayıt öncesi bir kere olmak üzere kişisel bilgi formu doldurdular ve her test başlangıcında bir kere, testin bitmesine yakın bir kere olmak üzere her uygulamada toplam iki kere öznel stres ölçeği uygulanmıştır. Sadece bir günkü kayıt için; bir gün öncesi spor yapmaları sağlanmış ve kalp atım hızı kayıdı alınmıştır. Katılımcılardan sadece gönüllüler rekreatif egzersizi uygulamıştır. Bu uygulama mesai sonrası 1 saat şirketin fitness salonunda hazırlanan hafif programla sınırlandırılmıştır. 1saat uygulanan bu çalışmada $20 \mathrm{dk}$ koşu bandında maksimal kalp atım hızı sayısının \%70 tempo koşu, $10 \mathrm{dk}$ bisiklet çevirme ve $30 \mathrm{dk}$ masa tenisi ile tamamlandırılmıştır. Bu program katılımcıların fazla zorlanmaması için sürekli kullandıkları aletlerle sınırlı tutulmuştur.

\section{Kalp Hızı Değişkenliği Kaydı}

Kalp hızı kayıtları için S810i Polar ${ }^{\circledR}$ saat kullanılmıştır. Bu kayıt şekliyle kalp vuruşları arasındaki süre (R-R aralığı) bir milisaniye ( $1 \mathrm{~ms})$ hassalığında kayıt edilmektedir.

Tablo 1. Tüm ölçümlerin kayıt süreleri. hata yüzdeleri ve toplam kalp atım sayıları

\begin{tabular}{lccccccccccccc}
\hline Değişkenler & \multicolumn{3}{c}{ Kayıt 1 } & \multicolumn{3}{c}{ Kayıt 2 } & \multicolumn{2}{c}{ Kayıt 3 } & \multicolumn{3}{c}{ Kayıt 4 } \\
\hline \multicolumn{1}{c}{} & N & Ort. & St.Sap. & N & Ort. & St.Sap. & N & Ort. & St.Sap. & N & Ort. & St.Sap. \\
\hline $\begin{array}{l}\text { Kayıt süresi } \\
\text { (dk) }\end{array}$ & 30 & 34.426 & 15.364 & 30 & 37.171 & 17.590 & 30 & 31.816 & 17.650 & 30 & 27.604 & 13.183 \\
$\begin{array}{l}\text { Hata } \\
\text { yüzdesi (\%) }\end{array}$ & 30 & .77 & .46 & 30 & .80 & .34 & 30 & .65 & .47 & 30 & .99 & .41 \\
$\begin{array}{l}\text { Toplam kalp } \\
\text { atım sayıSı }\end{array}$ & 30 & 2679.8 & 1227.0 & 30 & 2792.5 & 1447.2 & 30 & 2575.8 & 1745.6 & 30 & 2162.9 & 1097.2 \\
\hline
\end{tabular}


Her bir ölçümde değerlendirilen kayıt bölümündeki hatalı kalp atımı kayıt yüzdesi < \%1; buna bağlı olarak değerlendirmeye alınan kayıt süre ortalamaları her bir ölçüm için yaklaşık 30 dakika kadar olup aralarında istatistiksel olarak anlamlı bir fark yoktur (Friedman Testi, $\mathrm{p}>0.05)$.

\section{Stres Ölçeği}

Öznel stres ölçeği altı 11-nokta ölçeği kullanıldı $(0=$ hiç. asla; $10=$ en son. sonucu $)$ kullanıldı. (1) stresli, (2) gergin, (3) yorgun, bitkin, (4) dikkatini vermis, (5) motive edilmiş, (6) mutlu (Rissen ve ark., 2000). Öznel stres ölçeği ve fiziksel tepkiler ile korelasyonu bulundu (Lundberg, 1996). Öznel stres ölçeği oranlama tekniği 1980 y1lında Lundberg ve Frankenhauser tarafından geliştirmiştir. Araştırmacılar ölçek puanını fizyolojik parametrelerle ilişkili olduğunu bildirmektedirler. Gönüllü katılımcılar öznel stres ölçeğinde toplam altı soru yanıtlamışlardır. Sorularda kişinin işe odaklanması, yaptığı işiten memnuniyeti ve işe yeterliliği tespit edilmek amaçlı yapılan bir ölçek olmuştur.

\section{Kalp Hızı Değişkenliği Analizi}

Alınan kayıtlar Polar ${ }^{\circledR}$ yazılımı kullanılarak bir zaman dizisini dönüştürülmüş ve Kalp Hızı Değişkenliği parametreleri belirlenmiştir.

Tablo 2. Kalp hızı değişkenliğinin zaman boyutunda analiz verileri

Kalp Hızı Değişkenliği'nin zaman boyutu analizinde aşağıdaki parametreler değerlendirilmiştir.

Z1: Toplam kalp atım sayısı

Z2: En kısa R-R aralı̆̆ $(\mathrm{R}-\mathrm{Rmin})$

Z3: En uzun R-R aralı̆̆ (R-Rmaks)

Z4: Ortalama R-R aralığ $1\left(\mathrm{R}-\mathrm{R}_{\mathrm{ort}}\right)$

Z5: R-R aralığı standart sapması $\left(\mathrm{R}-\mathrm{R}_{\mathrm{sd}}\right)$

Z6: En uzun R-R aralığı ile en kısa R-R aralığı oranı $\left(\mathrm{R}_{\text {maks }} / \mathrm{R}_{\min }\right)$

Z7: Ardışık R-R aralığı karelerinin ortalamasının karekökü (RMSSD)

Z8: 50 ms' den fazla olan R-R aralık farklarının yüzdesi (pNN50)

Tablo 3. Kalp hızı değişkenliğinin frekans boyutunda analiz verileri

Kalp Hızı Değişkenliği’nin frekans boyutu analizi Fast Fourier Dönüşümü (FFD) ile elde edilen güç dağılımı üzerinden gerçekleştirilmiştir. Bu analizde aşağıdaki parametreler değerlendirilmiştir.

F1: 0.00-0.04 Hz arası düşük frekans bandı (VLF) gücü.

F2: 0.04-0.15 Hz arası düşük frekans bandı (LF) gücü.

F3: 0.15-0.40 Hz arası yüksek frekans bandı (HF) gücü.

F4: LF/HF oran1.

\section{Verilerin Analizi}

Tüm grubun tekrarlanan ölçüm parametrelerinin karşılaştırmaları için parametrik olmayan Friedman testi kullanılmıştır. Kategoriler arasındaki farkı belirlemek için ise MannWhitney U testi kullanılmıştır. Her iki test içinde anlamlılık sınırı $\mathrm{p}<0.05$ olarak kabul edilmiştir. Öznel stres ölçeği puanlarıyla kalp hızı değişkenliği ölçütleri arasındaki ilişkiyi 
belirlemek için Pearson korelasyonu kullanılmıştır. Bu test için ise anlamlılık sınırı p<0.01 olarak kabul edilmiştir.

\section{BULGULAR}

Tablo 4. Görev kodu değişkenine göre ardışık kalp atım aralığı farkı ortalamalarının karelerinin karekökü

\begin{tabular}{cccccc}
\hline Görev kodu & & 1. Kayıt & 2. Kayıt & 3. Kayıt & 4. Kayıt \\
\hline Yönetici & Ortalama & 25.027 & 22.400 & 24.811 & 22.086 \\
& $\mathbf{N}$ & 11 & 11 & 11 & 11 \\
& Stan. Sap. & 7.199 & 6.212 & 7.424 & 7.407 \\
& Ortanca & 22.900 & 22.700 & 28.300 & 21.800 \\
T. Elemanı & Ortalama & 34.447 & 31.774 & 33.750 & 31.420 \\
& N & 19 & 19 & 19 & 19 \\
& Stan. Sap. & 10.741 & 10.209 & 14.097 & 9.685 \\
& Ortanca & 37.300 & 29.900 & 30.450 & 27.700 \\
& Ortalama & 30.993 & 28.337 & 30.532 & 28.450 \\
& N & 30 & 30 & 30 & 30 \\
& Stan. Sap. & 10.526 & 9.955 & 12.718 & 9.900 \\
& Ortanca & 30.100 & 27.900 & 29.000 & 27.350 \\
\hline
\end{tabular}

Tablo 4'deki ardıșık kalp atım aralığı farkı ortalamalarının karelerinin karekökü ölçümleri açısından görev kodu değişkenliği arasında 1.ve 2. kayıtlarda anlamlı bir fark bulunmuştur $(\mathrm{p}<0.05)$.

Tablo 5. Görev kodu değişkenine göre ortalama ardışık kalp atım aralığı farkı ortalamalarının karelerinin karekökü için mann- whitney u testi sonuçları

\begin{tabular}{ccccc}
\hline & 1. Kayıt & 2.Kayıt & 3. Kaylt & 4. Kayıt \\
\hline Mann-Whitney U & 42.500 & 48.000 & 45.000 & 25.000 \\
Wilcoxon W & 108.500 & 114.000 & 90.000 & 53.000 \\
$\mathbf{Z}$ & -2.669 & -2.432 & -1.529 & -1.938 \\
p<(2-yönlü) & $.008^{*}$ & $.015^{*}$ & .126 & .053 \\
\hline
\end{tabular}

Tablo 5 'deki ardışık kalp atım aralığı farkı ortalamalarının karelerinin karekökü ölçümleri açısından görev kodu değişkenliği arasında 1.ve 2. kayıtlarda anlamlı bir fark bulunmuştur $(\mathrm{p}<0.05)$. 
Tablo 6. Görev kodu değişkenine göre HF izafi değeri

\begin{tabular}{cccccc}
\hline Görev kodu & & 1.Kaylt & 2.Kaylt & 3.Kaylt & 4.Kaylt \\
\hline Yönetici & Ortalama & 4.600 & 4.554 & 4.578 & 4.914 \\
& $\mathbf{N}$ & 11 & 11 & 11 & 11 \\
& Stan. Sap. & 1.612 & 2.122 & 2.071 & 3.027 \\
& Ortanca & 4.900 & 4.200 & 3.600 & 4.000 \\
T. Elemanı & Ortalama & 8.700 & 9.374 & 9.269 & 9.107 \\
& $\mathbf{N}$ & 19 & 19 & 19 & 19 \\
& Stan. Sap. & 4.376 & 4.804 & 5.729 & 5.053 \\
& Ortanca & 8.100 & 9.700 & 8.100 & 7.600 \\
Toplam & Ortalama & 7.197 & 7.606 & 7.580 & 7.773 \\
& $\mathbf{N}$ & 30 & 30 & 30 & 30 \\
& Stan. Sap. & 4.101 & 4.632 & 5.218 & 4.862 \\
& Ortanca & 6.100 & 6.300 & 6.800 & 6.900 \\
\hline
\end{tabular}

Tablo 6'daki HF izafi değer ölçümleri açısından görev kodu değişkenliği arasında 4 kayıtta da anlamlı bir fark bulunmuştur $(p<0.05)$. HF izafi değeri; frekans bandındaki değiskenliğin parasempatik sinir sistemi ve solunum etkisini yansitmaktadır.

Tablo 7. Görev kodu değişkenine göre ortalama HF izafi değerleri

\begin{tabular}{ccccc}
\hline & 1. Kayıt & $\begin{array}{c}\text { HF İzafi Değer } \\
\text { 2. Kayı }\end{array}$ & 3. Kayıt & 4. Kayılt \\
\hline Mann-Whitney U & 42.000 & 38.500 & 28.500 & 22.500 \\
Wilcoxon W & 108.000 & 104.500 & 73.500 & 50.500 \\
Z & -2.691 & -2.841 & -2.463 & -2.118 \\
P<(2-yönlü) & $.007^{*}$ & $.004^{*}$ & $.014^{*}$ & $.034^{*}$ \\
\hline
\end{tabular}

Tablo 7 'deki HF izafi değer ölçümleri açısından görev kodu değişkenliği arasında 4 kayıtta da anlamlı bir fark bulunmuştur $(\mathrm{p}<0.05)$.

Tablo 8. Öznel stres ölçeği dört ölçüm puanları

\begin{tabular}{lccc}
\hline & N & Ortalama & Standart Sapma \\
\hline 1.Ölçüm & 30 & 95.33 & 16.86321 \\
2.Ölçüm & 30 & 84.9333 & 17.93462 \\
3.Ölçüm & 30 & 92.8846 & 18.63401 \\
4.Ölçüm & 30 & 89.6000 & 14.98332 \\
\hline
\end{tabular}

Tablo 8’ da tüm ölçümlerin ortalama ve standart sapma değerleri verilmiştir. 
Tablo 9. Öznel stres ölçeği dört ölçüm puanları arasındaki korelasyon

\begin{tabular}{|c|c|c|c|c|c|}
\hline & & 1.Ölçüm & 2.ölçüm & 3.Ölçüm & 4.Ölçüm \\
\hline \multirow{3}{*}{ 1.Ölçüm } & $\begin{array}{c}\text { Pearson } \\
\text { Korelasyonu }\end{array}$ & & $.705(* *)$ & $.553(* *)$ & $.591(* *)$ \\
\hline & $\mathbf{P}<(2$-yönlü) & & .000 & .003 & .002 \\
\hline & $\mathbf{N}$ & & 30 & 30 & 30 \\
\hline \multirow{3}{*}{ 2.Ölçüm } & $\begin{array}{c}\text { Pearson } \\
\text { Korelasyonu }\end{array}$ & & & $.747(* *)$ & $.806(* *)$ \\
\hline & $\mathbf{P}<$ (2-yönlü) & & & .000 & .000 \\
\hline & $\mathbf{N}$ & & & 30 & 30 \\
\hline 3.Ölçüm & $\begin{array}{c}\text { Pearson } \\
\text { Korelasyonu } \\
\mathbf{P}<(2 \text {-yönlü) } \\
\text { N }\end{array}$ & & & & $\begin{array}{c}.791(* *) \\
.000 \\
30\end{array}$ \\
\hline
\end{tabular}

Tablo 9’ da (**) korelasyon 0.01 düzeyinde anlamlıdır. Öznel stres ölçeği dört ölçüm puanlarının her biri arasında kuvvetli pozitif yönde korelasyon mevcuttur; bu korelasyon 0.01 düzeyinde anlamlıdır.

Tablo 10. Cinsiyet değişkenine göre ardışık kalp atım aralığı farkı ortalamalarının karelerinin karekökü

\begin{tabular}{cccccc}
\hline Cinsiyet & & (1. Kayıt) & (2. Kayıt) & (3. Kayıt) & (4. Kayıt) \\
\hline Erkek & Ortalama & 28.9056 & 28.2389 & 25.9467 & 25.3750 \\
& $\mathbf{N}$ & 18 & 18 & 15 & 12 \\
& Stan. Sap. & 10.52987 & 10.83850 & 9.58450 & 7.93452 \\
& Ortanca & 26.7500 & 26.1500 & 25.4000 & 26.8500 \\
Kadın & Ortalama & 34.1250 & 28.4833 & 37.4100 & 32.1400 \\
& $\mathbf{N}$ & 12 & 12 & 10 & 10 \\
& Stan. Sap. & 10.14424 & 8.92747 & 14.17200 & 11.13595 \\
& Ortanca & 33.2000 & 29.6000 & 33.4500 & 27.5500 \\
Toplam & Ortalama & 30.9933 & 28.3367 & 30.5320 & 28.4500 \\
& $\mathbf{N}$ & 30 & 30 & 25 & 22 \\
& Stan. Sap. & 10.52589 & 9.95537 & 12.71832 & 9.90006 \\
& Ortanca & 30.1000 & 27.9000 & 29.0000 & 27.3500 \\
\hline
\end{tabular}

Tablo 10' de ortalama ve ortanca değerler incelendiğinde tüm dört kayıt için kadınlar lehine belirgin bir fark göze çarpmaktadır.

Tablo 11. Cinsiyet değişkenine göre ardışık kalp atım aralığı farkı ortalamalarının karelerinin karekökü için Mann-Whitney U Testi

\begin{tabular}{ccccc}
\hline & (1. Kayıt) & (2. Kayıt) & (3. Kayıt) & (4. Kayıt) \\
\hline Mann-Whitney & 74.500 & 102.000 & 31.000 & 40.000 \\
Wilcoxon W & 245.500 & 273.000 & 151.000 & 118.000 \\
$\mathbf{Z}$ & -1.419 & -.254 & -2.441 & -1.319 \\
$\mathbf{P}<$ (2-yönlü) & .156 & .799 & $.015^{*}$ & .187 \\
\hline
\end{tabular}


Tablo 11' da ortalama ve ortanca değerler incelendiğinde tüm dört kayıt için kadınlar lehine belirgin bir fark göze çarpmaktadır. Ardışık kalp atım aralığı farkı ortalamalarının karelerinin karekökü açısından erkekler ile kadınlar arasında 3. kayıtta anlamlı bir fark bulunmuştur $(\mathrm{p}<0.05)$.

Tablo 12. Cinsiyet değişkenine göre HF izafi değerleri

\begin{tabular}{cccccc}
\hline Cinsiyet & & $\mathbf{1 .}$ Kayıt & 2. Kayıt & 3. Kaylt & 4. Kayıt \\
\hline Erkek & Ortalama & 5.9111 & 6.2000 & 5.5 & 5.6917 \\
& $\mathbf{N}$ & 18 & 18 & 15 & 12 \\
& Stan. Sap. & 3.06630 & 3.55528 & 2.75500 & 2.66133 \\
& Ortanca & 5.8500 & 5.6000 & 5.0 & 5.4000 \\
Kadın & Ortalama & 9.1250 & 9.7167 & 10.7 & 10.2700 \\
& $\mathbf{N}$ & 12 & 12 & 10 & 10 \\
& Stan. Sap. & 4.80135 & 5.38024 & 6.54030 & 5.81283 \\
& Ortanca & 7.5000 & 8.2500 & 9.2 & 12.1500 \\
Toplam & Ortalama & 7.1967 & 7.6067 & 7.5800 & 7.7727 \\
& $\mathbf{N}$ & 30 & 30 & 25 & 22 \\
& Stan. Sap. & $\mathbf{4 . 1 0 1 2 6}$ & $\mathbf{4 . 6 3 2 4 9}$ & $\mathbf{5 . 2 1 8 0 8}$ & $\mathbf{4 . 8 6 1 6 3}$ \\
& Ortanca & $\mathbf{6 . 1 0 0 0}$ & $\mathbf{6 . 3 0 0 0}$ & $\mathbf{6 . 8 0 0 0}$ & $\mathbf{6 . 9 0 0 0}$ \\
\hline
\end{tabular}

Tablo 12' da ortalama ve ortanca değerler incelendiğinde tüm dört kayıt için kadınlar lehine belirgin bir fark göze çarpmaktadır.

Tablo 13. Cinsiyet değişkenine göre HF izafi değer ölçümleri için Mann-Whitney U Testi

\begin{tabular}{ccccc}
\hline & 1. Kaylt & 2. Kaylt & 3. Kayıt & 4. Kayıt \\
\hline Mann-Whitney U & 67.500 & 64.500 & 34.000 & 32.000 \\
Wilcoxon W & 238.500 & 235.500 & 154.000 & 110.000 \\
$\mathbf{Z}$ & -1.715 & -1.842 & -2.275 & -1.849 \\
$\mathbf{P}<(\mathbf{2}$-yönlü) & .086 & .065 & .023 & .064 \\
\hline
\end{tabular}

Tablo 13' de ortalama ve ortanca değerler incelendiğinde tüm dört kayıt için kadınlar lehine belirgin bir fark göze çarpmaktadır. HF izafi değer ölçümleri açısından erkekler ile kadınlar arasında 3. kayıtta anlamlı bir fark bulunmuştur $(p<0.05)$. Diğer kayıtlar içinde sınırda bir anlamlılık söz konusudur. 
Tablo 14. Sigara içme değişkenine göre ardışık kalp atım aralığı farkı ortalamalarının karelerinin karekökü

\begin{tabular}{cccccc}
\hline Sigara & & 1. Kayıt & 2. Kayıt & 3. Kayıt & 4. Kayıt \\
\hline İçiyor & Ortalama & 30.2385 & 30.8077 & 30.1833 & 26.8200 \\
& $\mathbf{N}$ & 13 & 13 & 12 & 10 \\
& Stan. Sap. & 10.75644 & 11.80406 & 15.14553 & 9.76841 \\
& Ortanca & 30.8000 & 29.9000 & 27.5000 & 27.3500 \\
İçmiyor & Ortalama & 31.5706 & 26.4471 & 30.8538 & 29.8083 \\
& $\mathbf{N}$ & 17 & 17 & 13 & 12 \\
& Stan. Sap. & 10.64059 & 8.14732 & 10.63043 & 10.22799 \\
& Ortanca & 28.5000 & 24.5000 & 29.2000 & 27.3500 \\
Toplam & Ortalama & 30.9933 & 28.3367 & 30.5320 & 28.4500 \\
& $\mathbf{N}$ & 30 & 30 & 25 & 22 \\
& Stan. Sap. & 10.52589 & 9.95537 & 12.71832 & 9.90006 \\
& Ortanca & 30.1000 & 27.9000 & 29.0000 & 27.3500 \\
\hline
\end{tabular}

Tablo 14' de kalp atım aralığı farkı ortalamalarının karelerinin karekökü değerleri ve sigara içme durumları arasında bir fark göze çarpmamaktadır.

Tablo 15. Sigara değişkenine göre ardışık kalp atım aralığı farkı ortalamalarının karelerinin karekökü değerleri için Mann-Whitney U Testi

\begin{tabular}{ccccc}
\hline & 1.Kayıt & 2.Kayıt & 3. Kaylt & 4. Kaylt \\
\hline Mann-Whitney U & 106.000 & 83.000 & 68.000 & 53.000 \\
Wilcoxon W & 197.000 & 236.000 & 146.000 & 108.000 \\
$\mathbf{Z}$ & -.188 & -1.151 & -.544 & -.462 \\
$\mathbf{P}<$ (2-yönlü) & .851 & .250 & .586 & .644 \\
\hline
\end{tabular}

Tablo 15'de ardışık kalp atım aralığı farkı ortalamalarının karelerinin karekökü değerleri ve sigara değişkeni arasında anlamlı bir farlılık bulunamamıştır $(p<0.05)$

\section{TARTIŞMA VE SONUÇ}

Günümüz yaşam koşulları ve çalışma hayatı stres faktörlerini yoğun olarak barındıran bir ortamdır. Stres anında insan vüdudunda kanda adrenalin ve sempatik sinirler arasında sinyal iletişimine yardımcı olan noradrenalin hormonu salgılanmakta. kan şekeri düzeyi. tansiyon ve kalp atışları yükselmekte ve solunum hızlanmaktadır (Rout, 2002). Fizyolojik ölçümlerin kaygı arastırmalarına getirdigi avantajlar şöyle açıklanmaktadır. Fizyolojik ölçümler, sözel ifadelere dayalı değillerdir ve bu nedenle sözel açıklama yeteneğinden bağımsızlardır. Kendi kendini gözleme yeteneği gerekli olmadığı için, hemen hemen tüm insanlarda kullanılabilirler. Davranışa paralel olarak sürekli değerlendirilebilirler. Ölçüm yapılırken, davranış bölünmek zorunda değildir (Hackfort \& Schwenkmezger, 1989). Bu bağlamda, bir fizyolojik parametre olarak kaygının göstergelerinden biri olan kalp atım hızı çalışması elde edilen verilerin objektifliği açısından yararlı olabilir (Landers ve ark., 1985). Zamana bağlı olarak kalp atımlarında gözlenen değişmeler, beyin ve kalp arasındaki dengenin anahtar bir ölçüsüdür. Kalp hızı değişkenliği (KHD), sinoatrial düğümdeki elektrik uyarılarının sağlıklı düzenlenip düzenlenmediğine işarettir. Otonom ve diğer fizyolojik sistemler tarafindan 
kardiyak fonksiyondaki düzeni, kalp atım sayısının ortalama değerlerde iken gözlenen dalgalanma miktarı ile ilgilidir (Lopes \& White, 2006). KHD akut strese duyarlı ve tepkisel bir özellik taşır. KHD'nin laboratuar şartlarında kesin karar vermeyi ve topluluk önünde konuşmayı gerektiren mental yüklenmelerde azaldığı bildirilmiştir (Malliani \& Pagani, 1991).

Hipotezimizde görev tanımı kategorisinde (Yönetici ve Takım Elemanı) ölçütler arasında istatistiksel olarak anlamlı bir fark yoktur teorisinden yola çıkılmıştır. Ancak ardışık kalp atım aralığı farkı ortalamalarının karelerinin karekökü ölçümleri açısından görev kodu değişkenliği arasında 1 . kayıt ve 2 . kayıtlarda anlamlı bir fark bulunmuştur $(p<0.05) . \mathrm{Bu}$ sonuçlar yönetici konumunda çalışanlarda kalp hızı değişkenliğinde anlamlı düşüşlere işaret etmektedir. Ciddi bir zihinsel yüklenmeye işaret eden bu bulgu literatür bilgileri ile uyumludur (Kageyama ve ark.,1998).

Ortalama ve ortanca değerler incelendiğinde tüm dört kayıt için kadınların lehine belirgin bir fark göze çarpmaktadır. Bu sonuçlar kalp hızı değişkenliği için kadınlar lehine bir farka işaret etmektedir. Ancak bu fark az sayıda ölçüt için istatistiksel olarak anlamlı düzeye ulaşmaktadır. HF izafi değer ölçümleri açısından erkekler ile kadınlar arasında 3. kayıtta anlamlı bir fark bulunmuştur $(\mathrm{p}<0.05)$. Diğer kayıtlar içinde sınırda bir anlamlılık söz konusudur. Literatür bulguları tarafından desteklenmektedir. Kadınların özellikle HF yüksek frekans parametresi erkeklerden daha yüksek değerler arz etse de zihinsel yüklenme sirasında bu cinsiyet farkı kaybolmaktadır (Sato, 2004). Diğer bir değişken olan sigara içme durumu ile kalp atım hızı değerleri arasında anlamlı bir farlılık bulunamamıştır. Genelde sigara kullanımının kalp hızı değişkenliğini düşürdüğü bildirilmekte, ancak bu etkide sedanter yaşam tarzının da katkısı olduğu düşünülmektedir (Gallagher, 1992).

Öznel stres ölçeği dört ölçüm puanlarının her biri arasında kuvvetli pozitif yönde korelasyon mevcuttur; bu korelasyon 0.01 düzeyinde anlamlıdır. Belirli uyarılmışlık seviyesinin sürekli olarak yaşandığı iş yerinde uyarılmanın KHD performansına etki ettiği ve buna bağlı olarak da kontrol performansını düşürdüğü ve stresi ortaya çıkardığı tespit edilmiştir.

Sonuç olarak çalışmada. iş yerinde zihinsel ve fiziksel yüklenmelere maruz kalan aynı işi yapan fakat farklı görev pozisyonlarda yer alan kişilerden elde edilen KHD değerlerinin karşılaştırılması ile en yüksek parasempatik aktivitenin ve olasılıkla zihinsel rahatlamanın tam olarak gerçekleşmediği anlaşılmaktadır. Dolayısıyla aşırı stres altındaki ve KHD değerleri normalin altında seyreden kişilerin sporu bir yaşam felsefesi haline getirmeleri önerilir.

Bu kadar yüksek tempoda çalışan kişilerin özellikle dikkat. konsantrasyon ve koordinasyon için spordan yararlanması önerilebilir. Yapılan çalışmada ferdi deneklerin kayıt çevrelerinin benzer olması sağlanmıştır. Çevresel değişkenler özenle kontrol edilmiş hep aynı konumunda kayıt alınarak. KHD araştırmaları bağlamında çalışmamızın geçerlilik ve güvenirlik düzeyi arttırılmıştır. Bununla birlikte. KHD’nin duyarlılığını, özgünlüğünü ve tahmin ediciliğini belirlemek için daha faz bulunmaktadır. 


\section{KAYNAKLAR}

Acharya, U. R., Kannathal, N., Sing, O.W., Ping, L.Y., \& Chua. T. (2004). Heart rate analysis in normal subjects of various age groups. Biomed Eng Online, 36(7), 1140-8.

Aronson, E., \& Wilson, T.D., (2012) Sosyal psikoloji çev. Okhan Gündüz. İstanbul: Kaknüs Yay.

Belkic, K., Landsbergis, P., Peter, R., Schnall, P., Baker, D., Theorell, T., Siegrist, J., \& Karesek, R.A. (2000). Reseach findings linking work- palce factors for CVD outcomes; psycholocial factors- review of the empirical data among men. Occup Med, 15, 24-46.

Cüceloğlu, D. (2011). Insan ve davranışı. İstanbul: Remzi Kitabevi, 22.

Frankenhaueuser, M., Lundberg, U., Augustson, H., Nilson, S., Hedman, H., \& Wahlstöm, K. (1989). Work, stress, job satisfaction. Swedish Work Environment Fund. Rest Grafiska. Stockholm pp 1-20.

Gallagher, D., Terenzi T., \& de Meersman, R. (1992). Heart rate variability in smokers, sedentary and aerobically fit individuals. Clin Auton Res., 2(6), 383-7.

Hackfort, D., \& Schwenkmezger, P. (1989). Measuring anxiety in sports: Perspectives and problems. AnXiety in Sports. (Edits). Hackfort. D., Spielberger. CD. New York: Hemisphere Publishing Corporation.

Hjortskov, N., Rissen, D., Blangsted, A.K, Fallentin, N., Lundberg, U., \& Sogaard. K. (2004). The effect of mental stress on heart rate variability and blood pressure during computer work. Eur J Appl Physiol, 92(1-2):84-9.

Johnson, J.V., \& Hall, E.M. (1988). Job strain. work place social support and cardiovaskular disease; a crosssectional study of a random sample of the Swedish working population. Am J Public Health, 78,1336- 1342.

Karasek, R.A. (1979). Job demans. job decision latitude and mental strain: implications for job redesing. Admin Sci Health 21:285-95.

Kageyama, T., Nishikido, N., Kobayashi, T., Kurokawa, Y., Kaneko, T., \& Kabuto, M. (1998). Self-reported sleep quality, job stress, and daytime autonomic activities assessed in terms of short-term heart rate variability among male white-collar workers. Ind Health, 36(3), 263-72.

Landers, D.M., Wang, M.O., \& Courtet, P. (1985). Peripheral narrowing among experienced and inexperienced rifle shooters under low- and high-stress conditions. Research Quarterly for Exercise and Sport, 56 (2), 122-130.

Lundberg, U. (1996). Influence of paid and unpaid work on psychophysiological stres responses of men and women. J Occup Health Psychol, 1, 117-130

Lopes, P., \& White, J. (2006). Heart rate variability measurement methods and practical implications. In: Maud PJ. Foster C. Physiological assessment of human fitness. 2nd edition, p: 39-61.

Malliani, A., Pagani, M., Lombardi, F., \& Cerutti, S., (1991). Cardiovascular neural regulation explored in the frequency domain. Circulation, 84, 1482-1492.

Rissen, D., Melin, B., Sandsjo, L., Dohns, I., \& Lundberg, U. (2000). Surface EMG and psychophysiological stress reactions in women during repetitive work. Eur J Appl Physiol, 83(2-3),215-22.

Rout, U.R., \& Rout, JK., (2002). Stress management for primary health care professionals. Hingham. MA. USA: Kluwer Academic Publishers, p 18.

Sato, N., \& Miyake, S. (2004). Cardiovascular reactivity to mental stress: relationship with menstrual cycle and gender. J Physiol Anthropol Appl Human Sci, 23(6), 215-23.

Srouffe, L.A. (1971). Effects of depth and rate of breathing on heart rate and heart rate variability. Psychophysiology, 8 (5), 648-55. 